\title{
Innovation of educational wound models for nursing students
}

\author{
Nongyao Kasatpibal ${ }^{* 1}$, Piyawan Sawasdisingha ${ }^{1}$, JoAnne D. Whitney ${ }^{2}$ \\ ${ }^{1}$ Division of Nursing Science, Faculty of Nursing, Chiang Mai University, Chiang Mai, Thailand \\ ${ }^{2}$ Department of Biobehavioral Nursing and Health Systems, School of Nursing, University of Washington, Seattle, WA, USA
}

Received: January 15, 2016

Accepted: April 24, $2016 \quad$ Online Published: May 17, 2016

DOI: $10.5430 /$ jnep.v6n9p101

URL: http://dx.doi.org/10.5430/jnep.v6n9p101

\begin{abstract}
Background: A clinical skills laboratory enhances the learning of nursing skills that can be translated to real professional practice. However, effective laboratory learning material that facilitates learners to achieve learning objectives may be inadequate in resource-limited settings. This study aimed to develop models for practicing wound dressing changes and to evaluate the quality of the model and user satisfaction.

Methods: The study was conducted in three phases: 1) preparing for model development, 2) model development, and 3) evaluation of the quality of the model and user satisfaction. Convenience sampling was used to recruit both nursing instructors and nursing students, 30, 10 and 271 participants in the first, second, and third phases, respectively. Focus group discussions were held to gain ideas and opinions for developing the models. A Likert scale questionnaire was used to evaluate the quality of the model and user satisfaction.

Results: The developed wound models were made from silicone. The quality evaluation form determined that the developed models had higher overall quality than those previous models available in the nursing laboratory center. User satisfaction with the developed models was high. The overall mean (SD) of user satisfaction toward the developed closed-wound model and open-wound model were $3.41(0.72)$ and 3.44 (0.71), respectively.

Conclusions: The developed wound models are potentially useful and user friendly, and could be easily available in settings of education with limited resources. Encouraging the students to use these models may help to enhance self-directed learning and clinical skills for application of wound dressings.
\end{abstract}

Key Words: Clinical skills laboratory, Educational material, Learning material, Wound dressing, Wound model

\section{INTRODUCTION}

A clinical skills laboratory (CSL) is important in preparing undergraduate nursing students for the real world of practice. ${ }^{[1,2]}$ CSL seems to be complicated for beginning nursing students because it requires not only knowledge and attitude of nursing students, but also critical thinking, and psychomotor and affective skills. ${ }^{[2-4]}$ A CSL is based on theoretical knowledge. Students then transfer their knowledge to psy- chomotor skills. ${ }^{[1]}$ In addition, nursing students require both theory and practice in the construction of their professional identity. ${ }^{[5]}$ It therefore challenges an instructor to create and deliver effective teaching experiences to the students using a student-centered approach for successful nursing education. ${ }^{[6]}$ A goal of instruction is to address student learning needs that encourage students in self-directed learning (SDL) and stimulates them by providing knowledge and informa-

\footnotetext{
* Correspondence: Nongyao Kasatpibal; Email: nongyaok2003@ gmail.com; Address: Division of Nursing Science, Faculty of Nursing, Chiang Mai University, Chiang Mai, Thailand.
}

Published by Sciedu Press 
tion, giving advice, and using educational approaches that arouse their interest and learning. However, several factors influence students' knowledge, attitude, and practice of psychomotor and affective skills. ${ }^{[1,2,7]}$

Educational media is a key factor affecting both teaching and learning because it acts as an intermediary in the transfer of knowledge, attitude, and skill from instructors to students, and enables students to achieve learning objectives. ${ }^{\left[{ }^{[8}\right.}$ Effective instruction, using appropriate educational media such as textbooks, videos, movies ${ }^{[8]}$ and realistic models ${ }^{[6,9]}$ along with engaging content can create a safe and productive learning environment and build up student self-confidence. ${ }^{[6,8,9]}$ Effective teaching and active learning facilitates students' engagement and more rapidly aids their correct understanding of complex skills and concepts. ${ }^{[9]}$ In addition, student retention of knowledge, interest in practice, and motivation for SDL are aided by effective learning methods. ${ }^{[6,8,9]}$

Recently, SDL has gained recognition in nursing CSL because education has been transformed from a teachercentered approach to a student-centered approach. ${ }^{[6]}$ In addition, many studies have documented that SDL is effective in adult learning and lifelong learning. ${ }^{[11,12]}$ Further reasons for increasing use of SDL are the significant increase in the number of nursing students, time constraints for CSL teaching and practice, and limited healthcare setting availability of practice. $^{[1,2]}$ Therefore, appropriate educational media and SDL is needed to improve CSL for nursing students ${ }^{[13,14]}$ because they can learn outside the classroom and it is the individual who is responsible for their own learning process by determining their needs, setting goals, identifying resources, implementing a plan to meet their goals, and evaluating the outcomes. $^{[13]}$

CSL teaching and SDL using a 3 dimensional model is preferable to using real objects because some CSL cannot be performed in actual real-life situations. ${ }^{[6,9]}$ In addition, a model can be handled, operated, and made bigger or smaller, thus making practice easy and convenient. ${ }^{[16]}$ Models are therefore used as one of the methods to enhance skills and build on expertise in nursing practice for nursing students prior to practice in real world performance.

A further significant factor that has impact on CSL is the learning environment including physical, psychosocial, and organizational aspects of the environment. ${ }^{[1,2,7]}$ Shortage of laboratory equipment may result in situations where concepts are poorly understood and/or there is insufficient skill training. ${ }^{2]}$ This situation frequently occurs in resource-limited training settings such as Thailand. In the setting for this study, approximately 150-200 nursing students enroll in each cohort and these are expanding. However, only two silicone closed-wound models (imported) are provided for CSL practice in wound dressing changes at the nursing laboratory center. Owing to the inadequate number of silicone wound models, the instructors supplemented training using foam models to have adequate educational media for students. Wounds were drawn on the foam models for CSL practice in applying wound dressings. The open-wound model in use was made of foam. Inadequate educational media and less realistic models may negatively impact the learning process and outcomes. ${ }^{[6,9]}$

Integration of SDL in CSL should help nursing students to more quickly develop psychomotor skills automatically because SDL is a process where individuals take the initiative without the help of others in diagnosing their learning needs, formulating goals, identifying human and material resources, and evaluating learning outcomes. ${ }^{[15]}$ SDL may help to empower nursing students to improve their responsibility to achieve learning objectives and to transfer their knowledge and skill from CSL to real world of practice. ${ }^{[1,6,9]}$ In addition, teaching that utilizes simulation should help to enhance clinical skills rapidly. ${ }^{[6]}$

Recently, simulation has been used globally for nursing procedure training due to limited opportunities to practice with real patients. Simulation provides a safe environment, unlimited time, increased opportunity, and options for practice (whole procedures or some parts of procedures). ${ }^{[6,9,17-19]}$ According to the framework for the use of simulation in technical skills learning, nursing students require five major components to form their skills in wound dressing: knowledgebased learning, task deconstruction, training in a laboratory environment, transfer of skills to the real environment, and granting privileged for independent practice. ${ }^{[17-19]}$ Effective simulation can help students gain experience and provide more realistic clinical practice for nursing students.

Wound dressing skill training should be successful if nursing students have a chance to practice frequently with a suitable model. Then they can learn to perform dressing change tasks reliably and automatically. However, this type of opportunity may be inadequate in settings that lack sufficient resources for simulation training.

In the study setting, an insufficient number of realistic wound models are available for practice. These may result in reduced opportunities for practice and make it more difficulty to transfer CSL to actual real world practice. In addition, a wound model that had been developed from other settings may be less well suited in the setting of this study due to contextual differences in instructors, students, and learning process. Therefore, this study aimed to increase the number of wound models, as well as create realistic models for 
wound dressing practice (closed-wound and open-wound), and to evaluate the quality of the model and user satisfaction. The newly developed wound models may act as stimuli for nursing students to promote CSL and SDL in wound dressing.

\section{Methods}

\subsection{Study setting and study design}

A developmental research design was implemented between October 2013 and April 2015. The study consisted of three phases, including 1) preparing for model development; 2) model development; and 3) evaluation of the quality of the model and user satisfaction. Convenience sampling was used to recruit nursing instructors from the Fundamental Nursing Department and Surgical Nursing Department who had teaching experience in the wound dressing laboratory; and the second, third, and fourth year Bachelor of Nursing degree students enrolled in the first semester of academic year 2014 who had learning experience in the wound dressing laboratory. The study recruited 30, 10 and 271 participants in the first, second, and third phases, respectively (see Table 1). The participants who had been a part of the focus group discussion were excluded from the evaluation of the new models. Written informed consent was obtained from all participants. Data collection was anonymous. This study was approved by the Ethical Review Committee for Research in Human Subjects, Faculty of Nursing, Chiang Mai University (No. 088/2014).

\subsection{Instruments}

Research instruments were developed by the principal investigator. All research instruments were validated by five experts, two nurse educators from the Fundamental Nursing Department, one nurse educator from the Surgical Nursing Department, and two wound care experts. A demographic data questionnaire was used to collect data from nursing instructors (department, gender, age, educational level, and teaching experience in wound dressing practice) and nursing students (gender, age, school year, and learning experience in wound dressing practice).

A focus group discussion guide: open-ended questions were used to gather information regarding problems of the clinical skill laboratory in practicing wound dressing changes, and wound models required to be developed such as material, shape, size, and color. In the first phase, the preparing for model development, two open-ended questions were asked: "What are the problems of the clinical skill laboratory in practicing wound dressing changes?" and "What are the characteristics of wound models required to be developed such as material, shape, size, and color?" In the second

Published by Sciedu Press phase, model development, only one open-ended question was asked: "What are your opinions on making any adjustments to the wound models relating to material, shape, size, and color?" The focus group discussion guide was piloted for feasibility in another nursing school in Chiang Mai.

Wound model quality evaluation questionnaire: This was a three-point rating scale (higher quality, the same quality, and lower quality compared to foam and silicone models available in nursing laboratory center) developed by the principal investigator to evaluate the quality of developed wound model. An example question was: "When comparing the developed closed-wound model with silicone (imported) closedwound model available in the laboratory center, please rate its quality for the following 10-items as higher, similar, or lower quality. Examples of the items were: 1) flexibility and tactile quality and 2) convenient to use, maintain, and transfer. The content validity index (CVI) of the quality evaluation questionnaire was .98 and Cronbach's Alpha Coefficient value of the quality evaluation questionnaire was .86 .

User satisfaction questionnaire: a four-point rating scale (extremely satisfied $=4$, very satisfied $=3$, moderately satisfied $=$ 2 , and slightly satisfied $=1$ ) questionnaire was developed by the principal investigator to examine user satisfaction. User satisfaction was interpreted using mean scores, extremely satisfied (3.51-4.00); very satisfied (2.51-3.50), moderately satisfied (1.51-2.50), and slightly satisfied (1.00-1.50). An example question was: "What is your satisfaction rating with the developed closed-wound model? Please rate your level of satisfaction for the following 10-items as extremely satisfied $=4$, very satisfied $=3$, moderately satisfied $=2$, and slightly satisfied $=1$. Examples of the items were: 1 ) flexibility and tactile quality and 2) convenient to use, maintain, and transfer. The CVI of the user satisfaction questionnaire was .99 and Cronbach's Alpha Coefficient value of the user satisfaction questionnaire was .94 .

Ten items were evaluated for the quality of the model and user satisfaction comprising flexibility and tactile quality; convenient to use, maintain, and transfer; restoration to the same condition after wound dressing practice; durability; reusing; cost saving; and attributes of shape and color representative of an actual wound.

\subsection{Data collection}

Information was gathered through focus group discussion in the first and the second phases. In the first phase, preparing for model development, two focus group discussions were conducted among nursing instructors (one group for fundamental faculty members and another group for surgical faculty members; six of each) and three focus group discus- 
sions of nursing students (one for the second year students, another for the third year students, and a third for the fourth year students; six of each) to discover the current problems of wound models used for wound dressing in the laboratory center, and to identify the material, shape, size, and color of new wound models required to be developed. In these focus group discussions, the principal investigator was a moderator and notes were taken and digitally recorded by a master degree nurse. Each participant had enough time to answer and discuss each question. The focus group discussions lasted on average 55 minutes (ranged 40-65 minutes).

In the second phase, a model was developed, based on the participants' responses from the first phase. Next, the researcher performed a trial in the development of educational wound models along with holding a focus group discussion with 10 participants some who had participated in the first phase (two fundamental faculty members, two surgical faculty members in one group, and two second year students, two third year students, and two fourth year students in another group) to offer suggestions on making any adjustments to the wound models relating to material, shape, size, and color. The researcher presented the developed wound models to all participants. Then, the researcher passed the wound models to all participants for looking and touching before providing feedback, and discussion. After that the researcher summarized and confirmed all suggestions with the participants. The wound models were modified according to the suggestions. Then, the researcher brought them back to the same participants for further suggestions in the third focus group discussion prior to evaluation of the models.

In the third phase, to evaluate the quality of the model and user satisfaction, a questionnaire eliciting responses on demographic data, wound model quality, and user satisfaction was distributed to 271 participants (14 nursing instructors and 257 nursing students).

\subsection{Data analysis}

The focus group discussions were transcribed and analyzed to identify relevant problems with the existing wound model and characteristics of the developed wound model. Demographic, quality of the model, and user satisfaction data were analyzed using descriptive statistics computing frequency, percentage, mean, standard deviation, and range. Quantitative data analysis was performed with SPSS, version 13.

\section{Results}

\subsection{Preparing for model development}

During the model preparation development phase, the participants provided very valuable information for the development of the wound models. It was concluded in the first focus group discussion that the models presently used in nursing skills laboratory in this setting were made of two types of materials silicone and foam. The participants reported that the quality of the silicone closed-wound model was fairly good, but it was heavy and difficult to transfer, and used for practicing only in the laboratory center. In addition, because it is an imported product the costs $(\$ 1,450$ per model) resulted in an inadequate number of closed-wound models for clinical skill laboratory practice in wound dressing. Owing to inadequate silicone wound models, the instructors used foam models instead to have adequate educational media for students and replicated wounds by drawing them on foam for nursing students to practice changing wound dressings. The open-wound model presently used was only made of foam. The participants noted that the attributes of the foam closed-wound model and the open one were not like those of real wounds. The foam model also made a squeaky sound from rubbing cotton against the foam which was not realistic. Additionally, some students pointed out that the inadequate wound model resulted in a long waiting time for performing practice. They therefore faced a limited time to practice wound dressing changes. This affected the students' anxiety, stress, and/or low self-confidence before return demonstration. For development of new wound models, the participants suggested that they be made of silicone. They further made suggestions on shape, size, and color of dressing wound models both closed-wound and open wound models.

\subsection{Model development}

Based on the participants' opinions, the researchers developed the wound models and asked the participants for further opinions and suggestions in the second and third group discussions. The participants suggested adjusting the shape of the open-wound model to become more realistic. They also suggested making a bigger closed-wound model to have adequate strapping area for plaster or other adhesive materials. The participants further gave their opinions that silicone material and light brown color of the wound models were appropriate. The final developed wound models used artificial skin composed of an outer layer of silicone and an inner layer of sponge, light brown color, and were located on a plastic base. The cost of the developed closed-wound and open-wound models were approximately $\$ 23$ and $\$ 28$, respectively. There was no breach of copyright in the creation of these developed wound models because we created and adjusted these models according to the information gathering from the participants of this study. In addition, all developmental processes including ingredients of artificial skin, shape, size, and color were created by ourselves. Therefore, the developmental processes and characteristics of these developed models were different from other available models. 


\subsection{Evaluation the quality of the model and user satis-}

\section{faction}

\subsubsection{Participants}

In total, 271 participants, 14 participants were the faculty instructors. Most instructors were female (92.9\%). The mean age was $41.9(+8.9$, range 28-62) years. Most of them held a doctoral degree $(57.1 \%)$. The instructors were mainly from the fundamental nursing department $(64.3 \%)$. The mean years of teaching experience in wound dressing laboratory was $12.8(+11.8$, rang 1-37) years. The remainder, 257 participants, were nursing students. Most students were female $(92.6 \%)$. The mean age was $21.0(+3.0$, range 19-46) years. Most of them were third year students $(47.9 \%)$, followed by fourth year students $(28.0 \%)$, and second year students (24.1\%) (see Table 1).

Table 1. Demographic characteristics of participants

\begin{tabular}{|c|c|c|c|c|c|c|}
\hline \multirow{2}{*}{ Demographic characteristics } & \multicolumn{2}{|c|}{$1^{\text {st }}$ phase Preparation $(n=30)$} & \multicolumn{2}{|c|}{$2^{\text {nd }}$ phase Development $(n=10)$} & \multicolumn{2}{|c|}{$3^{\text {rd }}$ phase Evaluation $(n=271)$} \\
\hline & $\mathbf{n}$ & $\%$ & $\mathbf{n}$ & $\%$ & $\mathbf{n}$ & $\%$ \\
\hline \multicolumn{7}{|l|}{ Teachers } \\
\hline \multicolumn{7}{|l|}{ Gender } \\
\hline Male & 1 & 8.3 & 1 & 25.0 & 1 & 7.1 \\
\hline Female & 11 & 91.7 & 3 & 75.0 & 13 & 92.9 \\
\hline \multicolumn{7}{|l|}{ Age (years) } \\
\hline$\leq 30$ & 1 & 8.3 & 1 & 25.0 & 1 & 7.1 \\
\hline $31-40$ & 4 & 33.3 & 1 & 25.0 & 4 & 28.6 \\
\hline $41-50$ & 6 & 50.0 & 1 & 25.0 & 7 & 50.0 \\
\hline $51-60$ & 1 & 8.3 & 1 & 25.0 & 1 & 7.1 \\
\hline$>60$ & 0 & 0.0 & 0 & 0.0 & 1 & 7.1 \\
\hline \multicolumn{7}{|l|}{ Educational level } \\
\hline Bachelor degree & 1 & 8.3 & 1 & 25.0 & 1 & 7.1 \\
\hline Master degree & 5 & 41.7 & 1 & 25.0 & 5 & 35.8 \\
\hline Doctoral degree & 6 & 50.0 & 2 & 50.0 & 8 & 57.1 \\
\hline \multicolumn{7}{|l|}{ Department } \\
\hline Fundamental nursing & 6 & 50.0 & 2 & 50.0 & 9 & 64.3 \\
\hline Surgical nursing & 6 & 50.0 & 2 & 50.0 & 5 & 35.7 \\
\hline \multicolumn{7}{|l|}{$\begin{array}{l}\text { Teaching experience in wound } \\
\text { dressing laboratory (years) }\end{array}$} \\
\hline $1-5$ & 1 & 8.3 & 1 & 25.0 & 1 & 7.1 \\
\hline $6-10$ & 3 & 25.0 & 1 & 25.0 & 2 & 14.3 \\
\hline $11-15$ & 4 & 33.3 & 1 & 25.0 & 4 & 28.6 \\
\hline $16-20$ & 4 & 33.3 & 1 & 25.0 & 5 & 35.7 \\
\hline$>20$ & 0 & 0.0 & 0 & 0.0 & 2 & 14.3 \\
\hline \multicolumn{7}{|l|}{ Students } \\
\hline \multicolumn{7}{|l|}{ Gender } \\
\hline Male & 7 & 38.9 & 3 & 50.0 & 19 & 7.4 \\
\hline Female & 11 & 61.1 & 3 & 50.0 & 238 & 92.6 \\
\hline \multicolumn{7}{|l|}{ Age (years) } \\
\hline 19 & 3 & 16.7 & 1 & 16.7 & 34 & 13.2 \\
\hline 20 & 4 & 22.2 & 1 & 16.7 & 87 & 33.9 \\
\hline 21 & 6 & 33.3 & 2 & 33.3 & 74 & 28.8 \\
\hline 22 & 4 & 22.2 & 1 & 16.7 & 53 & 20.6 \\
\hline$>22$ & 1 & 5.6 & 1 & 16.7 & 9 & 3.5 \\
\hline \multicolumn{7}{|l|}{ Academic year } \\
\hline $2^{\text {nd }}$ year & 6 & 33.3 & 2 & 33.3 & 62 & 24.1 \\
\hline $3^{\text {rd }}$ year & 6 & 33.3 & 2 & 33.3 & 123 & 47.9 \\
\hline $4^{\text {th }}$ year & 6 & 33.3 & 2 & 33.3 & 72 & 28.0 \\
\hline \multicolumn{7}{|l|}{$\begin{array}{l}\text { Learning experience in wound } \\
\text { dressing laboratory (years) }\end{array}$} \\
\hline 1 & 6 & 33.3 & 2 & 33.3 & 62 & 24.1 \\
\hline 2 & 6 & 33.3 & 2 & 33.3 & 123 & 47.9 \\
\hline 3 & 6 & 33.3 & 2 & 33.3 & 72 & 28.0 \\
\hline
\end{tabular}




\subsubsection{Quality of the model}

The quality evaluation form determined that $84.9 \%$ and $77.1 \%$ of users ranked the developed closed-wound model of higher overall quality than the silicone (imported) and foam models, respectively (see Tables 2-3). Most users ranked the developed open-wound model of higher overall quality than the foam model at $87.8 \%$ (see Table 4).

Table 2. Quality of developed closed-wound model comparison to imported closed-wound model $(\mathrm{n}=271)$

\begin{tabular}{|c|c|c|c|c|c|c|}
\hline \multirow{3}{*}{ Item } & \multicolumn{6}{|c|}{ Quality evaluation } \\
\hline & \multicolumn{2}{|c|}{ Higher } & \multicolumn{2}{|c|}{ Same } & \multicolumn{2}{|c|}{ Lower } \\
\hline & $\mathbf{n}$ & $\%$ & $\mathbf{n}$ & $\%$ & $\mathbf{n}$ & $\%$ \\
\hline $\begin{array}{l}\text { 1. Flexibility and } \\
\text { realistic to touch }\end{array}$ & 196 & 72.3 & 61 & 22.5 & 14 & 5.2 \\
\hline $\begin{array}{l}\text { 2. Convenient to } \\
\text { use }\end{array}$ & 203 & 74.9 & 58 & 21.4 & 10 & 3.7 \\
\hline $\begin{array}{l}\text { 3. Convenient to } \\
\text { maintain }\end{array}$ & 188 & 69.4 & 80 & 29.5 & 3 & 1.1 \\
\hline $\begin{array}{l}\text { 4. Convenient to } \\
\text { transfer }\end{array}$ & 201 & 74.2 & 62 & 22.9 & 8 & 2.9 \\
\hline $\begin{array}{l}\text { 5. Restoration to } \\
\text { the same condition } \\
\text { after use }\end{array}$ & 195 & 72.0 & 70 & 25.8 & 6 & 2.2 \\
\hline 6. Durability & 197 & 72.7 & 64 & 23.6 & 10 & 3.7 \\
\hline 7. Reuse & 201 & 74.2 & 64 & 23.6 & 6 & 2.2 \\
\hline 8. Cost saving & 177 & 65.3 & 56 & 20.7 & 38 & 14.0 \\
\hline $\begin{array}{l}\text { 9. Attribute shape } \\
\text { to real wound }\end{array}$ & 204 & 75.3 & 58 & 21.4 & 9 & 3.3 \\
\hline $\begin{array}{l}\text { 10. Attribute color } \\
\text { to real wound }\end{array}$ & 200 & 73.8 & 61 & 22.5 & 10 & 3.7 \\
\hline Overall Quality & 209 & 77.1 & 57 & 21.0 & 5 & 1.9 \\
\hline
\end{tabular}

Table 3. Quality of developed closed-wound model comparison to foam closed-wound model $(\mathrm{n}=271)$

\begin{tabular}{|c|c|c|c|c|c|c|}
\hline \multirow{3}{*}{ Item } & \multicolumn{6}{|c|}{ Quality evaluation } \\
\hline & \multicolumn{2}{|c|}{ Higher } & \multicolumn{2}{|c|}{ Same } & \multicolumn{2}{|c|}{ Lower } \\
\hline & $\mathbf{n}$ & $\%$ & $\mathbf{n}$ & $\%$ & $\mathbf{n}$ & $\%$ \\
\hline $\begin{array}{l}\text { 1. Flexibility and } \\
\text { realistic to touch }\end{array}$ & 232 & 85.6 & 26 & 9.6 & 13 & 4.8 \\
\hline $\begin{array}{l}\text { 2. Convenient to } \\
\text { use }\end{array}$ & 211 & 77.8 & 46 & 17.0 & 14 & 5.2 \\
\hline $\begin{array}{l}\text { 3. Convenient to } \\
\text { maintain }\end{array}$ & 214 & 79.0 & 45 & 16.6 & 12 & 4.4 \\
\hline $\begin{array}{l}\text { 4. Convenient to } \\
\text { transfer }\end{array}$ & 180 & 66.4 & 70 & 25.8 & 21 & 7.8 \\
\hline $\begin{array}{l}5 \text {. Restoration to } \\
\text { the same condition } \\
\text { after use }\end{array}$ & 235 & 86.7 & 23 & 8.5 & 13 & 4.8 \\
\hline 6. Durability & 234 & 86.4 & 22 & 8.1 & 15 & 5.5 \\
\hline 7. Reuse & 241 & 88.9 & 23 & 8.5 & 7 & 2.6 \\
\hline 8. Cost saving & 149 & 55.0 & 62 & 22.9 & 60 & 22.1 \\
\hline $\begin{array}{l}\text { 9. Attribute shape } \\
\text { to real wound }\end{array}$ & 217 & 80.1 & 42 & 15.5 & 12 & 4.4 \\
\hline $\begin{array}{l}\text { 10. Attribute color } \\
\text { to real wound }\end{array}$ & 228 & 84.1 & 29 & 10.7 & 14 & 5.2 \\
\hline Overall Quality & 230 & 84.9 & 25 & 9.2 & 16 & 5.9 \\
\hline
\end{tabular}

Table 4. Quality of developed open-wound model comparison to foam open-wound model $(n=271)$

\begin{tabular}{|c|c|c|c|c|c|c|}
\hline \multirow{3}{*}{ Item } & \multicolumn{6}{|c|}{ Quality evaluation } \\
\hline & \multicolumn{2}{|c|}{ Higher } & \multicolumn{2}{|c|}{ Same } & \multicolumn{2}{|c|}{ Lower } \\
\hline & $\mathbf{n}$ & $\%$ & $\mathbf{n}$ & $\%$ & $\mathbf{n}$ & $\%$ \\
\hline $\begin{array}{l}\text { 1. Flexibility and } \\
\text { realistic to touch }\end{array}$ & 232 & 85.6 & 26 & 9.6 & 13 & 4.8 \\
\hline $\begin{array}{l}\text { 2. Convenient to } \\
\text { use }\end{array}$ & 230 & 84.9 & 32 & 11.8 & 9 & 3.3 \\
\hline $\begin{array}{l}\text { 3. Convenient to } \\
\text { maintain }\end{array}$ & 224 & 82.6 & 36 & 13.3 & 11 & 4.1 \\
\hline $\begin{array}{l}\text { 4. Convenient to } \\
\text { transfer }\end{array}$ & 204 & 75.3 & 51 & 18.8 & 16 & 5.9 \\
\hline $\begin{array}{l}\text { 5. Restoration to } \\
\text { the same condition } \\
\text { after use }\end{array}$ & 225 & 83.0 & 35 & 12.9 & 11 & 4.1 \\
\hline 6. Durability & 239 & 88.2 & 18 & 6.6 & 14 & 5.2 \\
\hline 7. Reuse & 238 & 87.8 & 22 & 8.1 & 11 & 4.1 \\
\hline 8. Cost saving & 156 & 57.6 & 57 & 21.0 & 58 & 21.4 \\
\hline $\begin{array}{l}\text { 9. Attribute shape } \\
\text { to real wound }\end{array}$ & 235 & 86.7 & 25 & 9.2 & 11 & 4.1 \\
\hline $\begin{array}{l}\text { 10. Attribute color } \\
\text { to real wound }\end{array}$ & 236 & 87.1 & 23 & 8.5 & 12 & 4.4 \\
\hline Overall Quality & 238 & 87.8 & 24 & 8.9 & 9 & 3.3 \\
\hline
\end{tabular}

\subsubsection{User satisfaction}

User satisfaction with the developed models was at a very satisfied level. The overall mean (SD) scores of user satisfaction toward the developed closed-wound model and open-wound model, were $3.41(0.72)$ and $3.44(0.71)$, respectively (see Tables 5-6). There were no difference in the degree of satisfaction among the participants who had different in gender, age, and teaching/learning experience in both teachers and students.

\section{Discussion}

The development of wound models for wound dressing change practice enables us to have better models for teaching which will potentially enhance effectiveness of teaching and learning. It can be considered as an innovation in educational approach to improve learning through more realistic wound simulation. The findings showed that most of the participants assessed the quality of the developed wound models as better than that of the wound models previously used in the laboratory center and most of them had high satisfaction with the developed wound models on all items. This success may be related to the approach for model development that included identifying of existing problems gathering opinions of teachers and learners, and use of a critical analysis process to clearly pinpoint features before developing innovation. ${ }^{[20,21]}$ The approach of having both instructors and learners participate from the start in identifying problems about an educational model, and later in collaborative design as well as giving suggestions about the development of 
and adjustment to the innovation were conducive to having a quality innovation as required by the instructors and the learners. High quality of the model in terms of flexibility and being realistic to touch; convenient to use, maintain, and transfer; restoration to the same condition after wound dressing practice; and attributes of shape and color like an actual wound is an important factor facilitating students frequently perform CSL in wound dressing changes. ${ }^{[6,9]}$

Table 5. User satisfaction of developed closed-wound model $(\mathrm{n}=271)$

\begin{tabular}{|c|c|c|c|c|c|c|c|c|c|c|}
\hline \multirow{3}{*}{ Item } & \multicolumn{10}{|c|}{ Satisfaction level $^{*}$} \\
\hline & \multicolumn{2}{|c|}{4} & \multicolumn{2}{|c|}{3} & \multicolumn{2}{|c|}{2} & \multicolumn{2}{|c|}{1} & \multirow{2}{*}{$\bar{x}$} & \multirow{2}{*}{ SD } \\
\hline & $\mathbf{n}$ & $\%$ & $\mathbf{n}$ & $\%$ & $\mathbf{n}$ & $\%$ & $\mathbf{n}$ & $\%$ & & \\
\hline 1. Flexibility and realistic to touch & 126 & 46.5 & 119 & 43.9 & 22 & 8.1 & 4 & 1.5 & 3.35 & 0.70 \\
\hline 2. Convenient to use & 131 & 48.3 & 112 & 41.3 & 24 & 8.9 & 4 & 1.5 & 3.37 & 0.71 \\
\hline 3. Convenient to maintain & 131 & 48.3 & 114 & 42.1 & 23 & 8.5 & 3 & 1.1 & 3.38 & 0.69 \\
\hline 4. Convenient to transfer & 127 & 46.9 & 107 & 39.5 & 34 & 12.5 & 3 & 1.1 & 3.32 & 0.73 \\
\hline 5. Restoration to the same condition after use & 155 & 57.2 & 98 & 36.2 & 16 & 5.9 & 2 & 0.7 & 3.50 & 0.68 \\
\hline 6. Durability & 149 & 55.0 & 101 & 37.3 & 19 & 7.0 & 2 & 0.7 & 3.46 & 0.66 \\
\hline 7. Reuse & 161 & 59.4 & 94 & 34.7 & 13 & 4.8 & 3 & 1.1 & 3.52 & 0.65 \\
\hline 8. Cost saving & 99 & 36.5 & 88 & 32.5 & 70 & 25.8 & 14 & 5.2 & 3.00 & 0.93 \\
\hline 9. Attribute shape to real wound & 144 & 53.2 & 100 & 36.9 & 25 & 9.2 & 2 & 0.7 & 3.42 & 0.69 \\
\hline 10. Attribute color to real wound & 144 & 53.2 & 93 & 34.3 & 30 & 11.0 & 4 & 1.5 & 3.39 & 0.75 \\
\hline Overall Satisfaction & 143 & 52.8 & 102 & 37.6 & 21 & 7.7 & 5 & 1.9 & 3.41 & 0.72 \\
\hline
\end{tabular}

* 4 = extremely satisfied, 3 = very satisfied, 2 = moderately satisfied, 1 = slightly satisfied

Table 6. User satisfaction of developed open-wound model $(\mathrm{n}=271)$

\begin{tabular}{|c|c|c|c|c|c|c|c|c|c|c|}
\hline \multirow{3}{*}{ Item } & \multicolumn{10}{|c|}{ Satisfaction level* } \\
\hline & \multicolumn{2}{|c|}{4} & \multicolumn{2}{|c|}{3} & \multicolumn{2}{|c|}{2} & \multicolumn{2}{|c|}{1} & \multirow{2}{*}{$\bar{x}$} & \multirow{2}{*}{ SD } \\
\hline & $\mathbf{n}$ & $\%$ & $\mathbf{n}$ & $\%$ & $\mathbf{n}$ & $\%$ & $\mathbf{n}$ & $\%$ & & \\
\hline 1. Flexibility and realistic to touch & 128 & 47.2 & 121 & 44.7 & 18 & 6.6 & 4 & 1.5 & 3.38 & 0.68 \\
\hline 2. Convenient to use & 141 & 52.0 & 105 & 38.7 & 21 & 7.8 & 4 & 1.5 & 3.41 & 0.70 \\
\hline 3. Convenient to maintain & 132 & 48.7 & 106 & 39.1 & 30 & 11.1 & 3 & 1.1 & 3.35 & 0.72 \\
\hline 5. Restoration to the same condition after use & 150 & 55.4 & 100 & 36.9 & 18 & 6.6 & 3 & 1.1 & 3.46 & 0.68 \\
\hline 6. Durability & 159 & 58.7 & 92 & 33.9 & 17 & 6.3 & 3 & 1.1 & 3.50 & 0.67 \\
\hline 7. Reuse & 162 & 59.8 & 93 & 34.3 & 13 & 4.8 & 3 & 1.1 & 3.53 & 0.65 \\
\hline 8. Cost saving & 110 & 40.6 & 85 & 31.4 & 63 & 23.2 & 13 & 4.8 & 3.08 & 0.93 \\
\hline 9. Attribute shape to real wound & 147 & 54.2 & 100 & 36.9 & 21 & 7.8 & 3 & 1.1 & 3.44 & 0.69 \\
\hline Overall Satisfaction & 149 & 55.0 & 96 & 35.4 & 22 & 8.1 & 4 & 1.5 & 3.44 & 0.71 \\
\hline
\end{tabular}

* 4 = extremely satisfied, 3 = very satisfied, 2 = moderately satisfied, 1 = slightly satisfied

The approach used in this study may have influenced the high satisfaction level with the models in both teachers and learners. This may also explain why gender, age, and teaching/learning experience were not related to the degree of satisfaction because most of the participants had high level of satisfaction. This finding is inconsistent with a study reported that the students' satisfaction depend on teaching/learning experience. ${ }^{[22]}$ The teacher who had longer teaching experience may be able to organize excellent learning activities. In addition, they may be a good model in teaching CSL. These may lead to high satisfaction with CSL using the innova- tive wound models. Further reasons are the students who had more learning experience may have more knowledge and practice of skills as well as SDL skills. They may also have more self-confidence in CSL resulting in high satisfaction. ${ }^{[6,9,22]}$

This study was conducted in accordance with the innovation process and comprised of several systematic steps, starting from problem analysis to idea generation, idea evaluation, research planning, innovation development, and testing. However, it did not end with product marketing. ${ }^{[21,23]}$ This is because the major aim of this innovation was to elucidate a 
problem in CSL teaching and learning, it was not developed for purposes of commercializing wound models. It may be value added if this innovation is able to be marketed as an educational product in the future. A well-designed study examining the effectiveness of the wound models on knowledge and CSL should be performed prior to recommending generalized use of these models to ensure that they are truly valuable for achieving learning outcomes.

This study has shown that a focus group discussion can reveal a wealth of detailed information and deep insight into CSL problems in wound care, and gain ideas for developing and evaluation/testing of the wound models. A moderator plays an important role to lead the group and to allow the participants to agree or disagree with each other so that it provides an insight into how a group thinks about an issue. The strategies used for developing wound models in this study can be applied to other settings, especially in resource-limited countries that may need to develop their own educational model.

The innovative models provide sufficient number of models for the students to practice in our nursing laboratory center and allow the students to borrow the models to practice outside the laboratory center. It therefore increases opportunities for students to practice and improve clinical skills. In addition, our laboratory center provides the developed models for educating new and experienced nurses as well as patients in the hospital and patient's home. According to a theory of motor skill acquisition, intensive practice helps to reinforce skills rapidly. ${ }^{[24]}$ This theory has been broadly acknowledged for technical skills teaching. It has been proposed for the three stages of learning model. The first 'cognitive' stage, focuses on cognitively oriented problems. The learner begins the experience with many errors and the procedure is performed consciously but not with competence. The second 'associative' stage, occurs when the learner translates their knowledge and demonstrates proper motor skill. However, the skill requires a great deal of concentration, but some parts of the skill are automatically controlled. The third 'autonomous' stage, is achieved after the learner practices extensively. The skill is performed smoothly and continuously and most parts of skill are automatically controlled. ${ }^{[17,24,25]}$ Facilitating allocation and organization of the environment together with adequate well designed equipment and motivation are needed to engage students in effective CSL in wound dressing changes. ${ }^{[2]}$

Recently, CSL and SDL have gained importance in nursing education ${ }^{[26,27]}$ because of increasing the numbers of nursing students, ${ }^{[28]}$ time constraints, and limited settings to authenticate clinical skills. ${ }^{[2]}$ Therefore, nursing schools are investing in nursing laboratory centers to facilitate learning resources for nursing students from fundamental to advanced CSL. However, there is great diversity across schools due to differences in teaching programs and available financial support. If the laboratory center can create an environment similar to the actual future workplace, the students may be better able to apply their CSL in the real situations without difficulty. ${ }^{[1,2]}$ On the other hand, if it is not applicable, the students may experience frustration and reduced satisfaction with CSL. ${ }^{[2]}$ It is therefore important to build authenticity in models and training environments for the students. ${ }^{[29]}$ Instructors should create appropriate physical environment, psychosocial environment, and organizational environment to promote CSL and SDL for nursing students.

Our study has some limitations. Firstly, this study was conducted at a single university in Thailand and therefore the results may not be generalized to other settings. However, the concept and methodology used in this study may be relevant to other resource-limited settings with similar contexts. Another limitation is only a short term evaluation of the quality of the model and user satisfaction could be documented due to timeframe constraint. The findings suggest that a longitudinal study should be performed to examine long term quality of the models and their effectiveness on learning outcomes such as knowledge and CSL to ensure that the novel models are truly effective.

\section{Conclusion}

This study indicated that the newly developed wound models had higher quality than those previous models available in the nursing laboratory center and user satisfaction was at a high level. The models are potentially useful and could be easily available in settings of education with limited resources. Instructors should encourage the students to use the innovative developed wound models in CSL practice. This is not only to promote CSL and SDL, but also to enhance their clinical practice skills to gain self-confidence prior to delivering nursing care to clients.

\section{ACKNOWLEDGEMENTS}

The authors would like to thank Mr. Ong-arg Silapa, Faculty of Medicine, Chiang Mai University, who plays a key role in making the dressing wound models and nursing faculty instructors and students who participated in this study as well as those involved in the successful completion of this study. This study was funded by Faculty of Nursing, Chiang Mai University, Thailand.

\section{CONFLicts OF INTEREST Disclosure}

The authors declare that there is no conflict of interest. 


\section{REFERENCES}

[1] Ewertsson M, Allvin R, Holmström IK, et al. Walking the bridge: nursing students' learning in clinical skill laboratories. Nurse Educ Pract. 2015; 15(4): 277-283. PMid:25892366. http://dx.doi.o rg/10.1016/j.nepr.2015.03.006

[2] Haraldseid C, Friberg F, Aase K. Nursing students' perceptions of factors influencing their learning environment in a clinical skills laboratory: a qualitative study. Nurse Educ Today. 2015; 35(9): e1-e6. http://dx.doi.org/10.1016/j.nedt.2015.03.015

[3] Forehand M. Bloom's taxonomy: original and revised. In Orey M, editor. Emerging perspectives on learning, teaching, and technology. 2010. p. 41-47. [cited 2015 May 30]. Available from: https://textbookequity.org/oct/Textbooks/Orey_ Emergin_Perspectives_Learning.pdf

[4] Ross JG. Simulation and psychomotor skill acquisition: a review of the literature. Clin Simul Nurs. 2012; 8(9): e429-e435. http: //dx.doi.org/10.1016/j.ecns.2011.04.004

[5] Arreciado Marañón A, Isla Pera MP. Theory and practice in the construction of professional identity in nursing students: a qualitative study. Nurse Educ Today. 2015; 35(7): 859-863. PMid:25863650. http://dx.doi.org/10.1016/j.nedt.2015.03.014

[6] Jeffries PR, Clochesy JM. Clinical simulations: an experiential, student-centered pedagogical approach. In: Billings DM, Halstead JA, editor. Teaching in nursing: a guide for faculty. 4th ed. (pp. 352-368). St. Louis (MO): Elsevier Health Sciences; 2012.

[7] Stokes LG, Kost GC. Teaching in the clinical setting. In Billings D, Halstead J, editors. Teaching in nursing: a guide for faculty. 4th ed. St. Louis (MO): Elsevier Saunders; 2012. p. 311-334.

[8] Farhadi N. The role of educational media in teaching-learning. EJAE. 2014; 1(6): 18-21.

[9] Jeffries PR. Simulation in nursing education: from conceptualization to evaluation. 2nd ed. New York (NY): National League for Nursing; 2012.

[10] Bonwell CC, Eison JA. Active learning: creating excitement in the classroom. Washington (DC): George Washington University Press; 1991.

[11] Mezirow J. Transformative learning: theory to practice. In: Cranton $\mathrm{P}$, editor. Transformative learning in action: insights from practice. New Directions for Adult and Continuing Education No. 74. San Francisco (CA): Jossey-Bass; 1997. p. 5-12.

[12] Taylor E. Analyzing research on transformative learning theory. In Mezirow J, Associates editors. Learning as transformation: critical perspectives on a theory in progress. San Francisco (CA): JosseyBass; 2000. p. 285-328.

[13] Cadorin L, Rei A, Dante A, et al. Enhancing self-directed learning among Italian nursing students: a pre- and post-intervention study. Nurse Educ Today. 2015; 35(6): 746-753. PMid:25735910. http://dx.doi.org/10.1016/j.nedt.2015.02.004

[14] Cheng SF, Kuo CL, Lin KC, et al. Development and preliminary testing of a self rating instrument to measure self-directed learning ability of nursing students. Int J Nurs Stud. 2010; 47(9): 1152-
1158. PMid:20223455. http://dx.doi.org/10.1016/j.ijnur stu. 2010.02.002

[15] Knowles MS. The making of an adult educator. San Francisco (CA): Jossey-Bass; 1989.

[16] Jalihal KA, Veerabhadraiah V. Fundamentals of extention education and management in extension. New Delhi: Concept Publishing Company; 2007.

[17] Castanelli DJ. The rise of simulation in technical skills teaching and the implications for training novices in anaesthesia. Anaesth Intensive Care. 2009; 37: 903-910. PMid:20014595.

[18] Aggarwal R, Darzi A. Technical-skills training in the 21st century. N Engl J Med. 2006; 355: 2695-2696. PMid:17182997. http: //dx.doi.org/10.1056/NEJMe068179

[19] Aggarwal R, Grantcharov TP, Darzi A. Framework for systematic training and assessment of technical skills. J Am Coll Surg. 2007; 204: 697-705. PMid:17382230. http://dx.doi.org/10.1016/j .jamcollsurg.2007.01.016

[20] Rogers EM. Diffusion of innovations. 5th ed. New York (NY): Free Press; 2003.

[21] Tidd J, Bessant J. Managing innovation: integrating technological, market and organizational change. 5th ed. New York (NY): Wiley; 2013.

[22] Cremonini V, Ferri P, Artioli G, et al. Nursing students' experiences of and satisfaction with the clinical learning environment: the role of educational models in the simulation laboratory and in clinical practice. Acta Biomed. 2016; 86(3 Suppl): 194-204.

[23] Tiwari R. The innovation process. [cited 2015 May 30]. Available from: http: //www.global-innovation.net/innovation/

[24] Newell KM. Motor skill acquisition. Annu Rev Psychol. 1991; 42 213-237.

[25] Reznick RK, MacRae H. Teaching surgical skills-changes in the wind. N Engl J Med. 2006; 355: 2664-2669. PMid:17182991. http://dx.doi.org/10.1056/NEJMra054785

[26] Avdal EÜ. The effect of self-directed learning abilities of student nurses on success in Turkey. Nurse Educ Today. 2013; 33(8): 838-841. PMid:22405343. http://dx.doi.org/10.1016/j.ned t. 2012.02 .006

[27] Wellard SJ, Heggen KM. Are laboratories useful fiction? A comparison of Norwegian and Australian undergraduate nursing skills laboratories. Nurs Health Sci. 2010; 12(1): 39-44. PMid:20487324. http://dx.doi.org/10.1111/j.1442-2018.2009.00481.x

[28] Lin ZC. Comparison of technology-based cooperative learning with technology based individual learning in enhancing fundamental nursing proficiency. Nurse Educ Today. 2013; 33(5): 546-551. PMid:22260882. http://dx.doi.org/10.1016/j.nedt. 2011 .12 .006

[29] Wellard SJ, Solvoll BA, Heggen KM. Picture of Norwegian clinical learning laboratories for undergraduate nursing students. Nurse Educ Pract. 2009; 9(4): 228-235. PMid:18700184. http://dx .doi .org /10.1016/j.nepr.2008.06.005 